\title{
Surfactant therapies for pediatric and neonatal ARDS: ESPNIC expert consensus opinion for future research steps
}

\author{
Daniele De Luca ${ }^{1,2^{*}} \mathbb{C}$, Paola Cogo ${ }^{3}$, Martin C. Kneyber ${ }^{4,5}$, Paolo Biban ${ }^{6}$, Malcolm Grace Semple7, \\ Jesus Perez-Gil ${ }^{8}$, Giorgio Conti ${ }^{9}$, Pierre Tissieres ${ }^{10,11}$ and Peter C. Rimensberger ${ }^{12}$
}

\begin{abstract}
Pediatric (PARDS) and neonatal (NARDS) acute respiratory distress syndrome have different age-specific characteristics and definitions. Trials on surfactant for ARDS in children and neonates have been performed well before the PARDS and NARDS definitions and yielded conflicting results. This is mainly due to heterogeneity in study design reflecting historic lack of pathobiology knowledge. We reviewed the available clinical and preclinical data to create an expert consensus aiming to inform future research steps and advance the knowledge in this area. Eight trials investigated the use of surfactant for ARDS in children and ten in neonates, respectively. There were improvements in oxygenation (7/8 trials in children, 7/10 in neonates) and mortality (3/8 trials in children, 1/10 in neonates) improved. Trials were heterogeneous for patients' characteristics, surfactant type and administration strategy. Key pathobiological concepts were missed in study design. Consensus with strong agreement was reached on four statements:
\end{abstract}

1. There are sufficient preclinical and clinical data to support targeted research on surfactant therapies for PARDS and NARDS. Studies should be performed according to the currently available definitions and considering recent pathobiology knowledge.

2. PARDS and NARDS should be considered as syndromes and should be pre-clinically studied according to key characteristics, such as direct or indirect (primary or secondary) nature, clinical severity, infectious or noninfectious origin or patients' age.

3. Explanatory should be preferred over pragmatic design for future trials on PARDS and NARDS.

4. Different clinical outcomes need to be chosen for PARDS and NARDS, according to the trial phase and design, trigger type, severity class and/or surfactant treatment policy.

We advocate for further well-designed preclinical and clinical studies to investigate the use of surfactant for PARDS and NARDS following these principles.

Keywords: Neonate, Infant, Children, PARDS, NARDS, Surfactant

\footnotetext{
*Correspondence: dm.deluca@icloud.com

${ }^{1}$ Division of Pediatrics and Neonatal Critical Care, "A.Béclère"Medical

Centre, Paris Saclay University Hospitals, APHP, 157 Rue de la Porte de Trivaux, 92140 Clamart (Paris-IDF), France

Full list of author information is available at the end of the article
}

\section{Background}

Acute respiratory distress syndrome (ARDS) occurs at any age including pediatric (PARDS) and neonatal (NARDS) patients, and age-specific definitions of the syndrome are now available, namely the pediatric acute lung injury consensus conference (PALICC) and the Montreux definition for PARDS and NARDS, respectively [1, 
2]. PALICC and Montreux definitions should be used, respectively, for children beyond the first month of age and for neonates from birth until 4 weeks, or 44 weeks post-menstrual age if born before 40-weeks' gestation (Additional file 1) [3]. ARDS is a life-threatening respiratory failure characterized by lung tissue inflammation [4] and alveolar and/or endothelial damage [5] coupled with a complex surfactant injury [6]. In children and neonates, these features may translate in different epidemiology, triggers and clinical approach $[1,7,8]$. For example, direct or pulmonary (primary) and indirect or extrapulmonary (secondary) ARDS may have peculiar triggers in children and neonates, such as meconium aspiration, bronchiolitis or necrotizing enterocolitis. Lung tissue in children is less prone to inflammation and fibrosis, while the relative volume is smaller as the alveolarization is still ongoing [9]. Endogenous surfactant is present in relatively higher concentrations, and similarly, higher doses of exogenous surfactant are more easily administered [9].

Despite these peculiarities, ARDS pathobiology pattern (inflammation, cellular damage and surfactant dysfunction) is the same in patients of any age. Inflammation and cellular damage also contribute to surfactant qualitative and quantitative injury, affecting both surfactant proteins and phospholipids [10]. From a molecular point of view, phospholipases, proteases, inflammatory mediators and oxygen reactive species play a role in this damage $[3,7]$. Once the injury has been triggered, a vicious cycle drives ARDS: (1) phospholipase-driven surfactant phospholipid hydrolysis; (2) production of free fatty acids; and (3) derived inflammatory mediators; (4) further surfactant damage due to inflammatory mediators [12]. This 'surfactant catabolism-inflammation-surfactant catabolism' mechanism can perpetuate the injury and worsen the loss of alveolar-capillary barrier function. This, in its turn, facilitates the cellular influx toward the lung and the accumulation of proteins within the interstitial and alveolar space. Neutrophils and alveolar macrophages may increase the local inflammation, worsening the vicious cycle. In fact, in vivo studies on adult ARDS patients showed that disaturated phosphatidylcholine turnover is faster compared to controls, due to increased surfactant catabolism [13]. These mechanisms represent the 'exudative phase' of ARDS. They cause an increase in alveolar surface tension and a reduction in lung compliance. This pathobiology is known to be different between direct and indirect ARDS as the two types of the syndrome have distinct cellular and biochemical injury profile [14-16]. Data in pediatric patients are more limited but consistent and also indicated differences between ARDS of infectious or non-infectious origin [17]. Later, in the severest cases, the picture may eventually evolve into the 'fibroproliferative phase' characterized by the formation of hyaline membranes, influx of proliferating mesenchymal cells, epithelial cell necrosis/apoptosis, thrombogenesis in pulmonary vessels and lung fibrosis. This phase may occur within 3-4 days of injury in some parts of the lung and can overlap with the exudative phase in other parts of the lung. Given this pathobiology, it is not surprising that surfactant has been considered a potential therapeutic agent for the early phase of ARDS, to reverse the surfactant dysfunction, improve compliance and (re-) open the alveoli, allowing better gas exchange and/or less aggressive respiratory support.

So far, attempts to cure ARDS with surfactant have not led to impressive results. This was likely due to many reasons such as: 1) lack of efficient alveolar surfactant delivery; 2) inactivation of surfactant by phospholipase A2 and other surfactant-injuring agents; 3 ) insufficient dose; 4) wrongful trial design. This latter may be due to several issues, but undoubtedly a main one is represented by lack of homogeneity as trials included very different patients, types of ARDS, surfactant preparations, comorbidities and co-interventions [18]. There is effort to find 'enrichment tools' (such as biomarkers or imaging techniques) to better describe ARDS populations in adult critical care [19], and this is definitively needed for patients of any age.

Several studies on the use of surfactant for ARDS in children and neonates have been published. Nonetheless, despite the pediatric/neonatal experience being wider than that of adult medicine, evidence in favor of surfactant is still unavailable [20]. We aim to analyze data to offer an expert consensus opinion suggesting how to advance the knowledge in pediatric (PARDS) and neonatal (NARDS) ARDS field.

\section{Methods}

We planned to perform a narrative review about surfactant for ARDS in children and neonates, and based on this, to create a consensus opinion about future research steps in this field. The European Society for Pediatric and Neonatal Intensive Care (ESPNIC) created an expert committee, including two intensivists skilled in relevant methodology, as in previous ESPNIC guidelines [21]. The project was divided into two phases: (1) review of the literature and (2) production of expert consensus opinion. Since well-known trials' heterogeneities prevent data aggregation [20], we did not perform any quantitative meta-analysis or bias assessment. This is consistent with our aim which was not to give any advice on clinical efficacy. We focused: on (1) any translational or animal study on surfactant biology during ARDS and (2) randomized controlled trials comparing surfactant therapy versus standard care for ARDS in children and neonates, irrespective of definition used to diagnose the syndrome. 
We decided so because PARDS and NARDS definition are quite recent; thus, many clinical studies had to be based on different entry criteria. Studies about the firstgeneration, protein-free surfactants have been excluded as they are no longer marketed and were not used in ARDS trials. These surfactants are clinically inferior to animal surfactant preparations, which contain higher amount of proteins, in preterm neonates with respiratory distress syndrome (RDS, i.e., hyaline membrane disease due to primary surfactant deficiency) [22]. Moreover, ARDS patients also show decreased levels of surfactant proteins; thus, protein-free surfactants are likely to be less efficacious to treat ARDS, as well [23]. Quaker-based technique [24] was used for panel discussion, and recommendations were voted as in previous ESPNIC guidelines [21]. Panel composition, literature review and consensus methodology are detailed in Additional file 2.

\section{Results}

Literature review

Additional file 3 reports the basic data of clinical trials included in the review. Trials were very heterogeneous for patients' age, type of ARDS, entry criteria and case mix, surfactant type, dose and administration technique, injected volume and ventilatory policy. These are main points that may have prevented to have solid results. In particular, patients' age was especially variable in pediatric trials, with one expanding enrolment beyond pediatric age (including patients with malignances up to 25 years old) [25]. Ventilatory strategy is also variable and, notably, often not protocolized and left to the decision of attending physicians in neonatal trials. Table 1 summarizes the characteristics of surfactant preparations trialed for ARDS in children and neonates as bolus administration or broncho-alveolar lavage. Six natural and one synthetic surfactant have been used. Animal-derived surfactants were either bovine or porcine and produced with various techniques. Surfactant preparations have extremely variable phospholipid profile and protein concentrations [26]. The synthetic surfactant (lucinactant) contains a synthetic peptide $\left(\mathrm{KL}_{4}\right.$ or sinapultide) designed to mimic the sequence pattern of amphipathic helix of SP-B. Sinapultide is a 21-amino-acid hydrophobic synthetic peptide consisting of four leucine (L) and a lysine (K) repeating units. Moreover, it has a simple phospholipid profile, consisting of only dipalmitoylphosphatidylcholine, 1-palmitoyl-2-oleoyl-sn-glycero-3-phosphoglycerol and palmitic acid.

Tables 2 and 3 summarize the review results: eight and ten trials investigated the use of surfactant for ARDS in children [25, 27-33] and neonates [34-43], respectively. Notably, one manuscript was not considered because it was a subgroup post hoc analysis of another trial [44].

None of the pediatric trials used the PALICC definition specific to PARDS [2]. Surfactant improved oxygenation in almost all these trials [25, 27-33], and mortality was lowered in 3 out of 8 trials [28-30]; other respiratory outcomes were also often ameliorated. Biochemical and biophysical parameters were not studied.

The Montreux definition of NARDS was released in 2017 and only one trial used it [43]. All the other neonatal trials enrolled patients with respiratory disorders appearing as NARDS but defined with variable criteria. Only one trial provided mortality data and showed improvement [41], and only one provided some biological or biophysical results [34]. Surfactant improved oxygenation in the 7 out of 10 trials [35, 37-40,40-43]. Other outcomes were ameliorated in 6 trials [34-36, 38, 41, 42].

\section{Expert consensus}

The following statements were approved:

1. There are sufficient preclinical and clinical data to support targeted research on surfactant therapies for

Table 1 Characteristics of surfactants trialed for ARDS, in children and neonates as bolus and/or broncho-alveolar lavage

\begin{tabular}{|c|c|c|c|c|c|c|c|}
\hline Chemical name & Manufacturer & Country & Origin & Production method & $\mathrm{PL}(\mathrm{mg} / \mathrm{mL})$ & $\begin{array}{l}\text { Tested } \\
\text { in children }\end{array}$ & $\begin{array}{l}\text { Tested } \\
\text { in neonates }\end{array}$ \\
\hline Beractant & Abbvie & USA & Bovine & Minced lung & 25 & Yes & Yes \\
\hline Bovactant & Boehringer Ingelheim Pharma & Germany & Bovine & Lung lavage & 45 & Yes & No \\
\hline Calfactant & ONY/Pneuma Pharmaceuticals & USA & Bovine (calf) & Lung lavage & 35 & Yes & No \\
\hline $\begin{array}{l}\text { Kelisu (Calf } \\
\text { Surfactant for } \\
\text { injection) }\end{array}$ & CR Double Crane & China & Bovine (calf) & Lung lavage & 30 & No & Yes \\
\hline Lucinactant & Discovery Lab & USA & Chemical & Synthetic & 30 & Yes & No \\
\hline Poractant-a & Chiesi Farmaceutici & Italy & Porcine & Modified minced lung & 80 & Yes & Yes \\
\hline Surface & CENSA & Cuba & Porcine & Lung lavage & 25 & Yes & No \\
\hline
\end{tabular}

Abbreviations: PL: phospholipids 
Table 2 Synthesis of results: surfactant therapy in children

\begin{tabular}{|c|c|c|c|c|}
\hline Author/year & $\begin{array}{l}\text { Type of } \\
\text { surfactant }\end{array}$ & Oxygenation & Mortality & $\begin{array}{l}\text { Secondary } \\
\text { respiratory } \\
\text { outcomes }\end{array}$ \\
\hline Willson [27] & Calfactant & $\begin{array}{l}\text { Improved } \\
(-50 \% \mathrm{OI})\end{array}$ & Unchanged & $\begin{array}{l}\text { Shorter } \\
\text { ventilation and } \\
\text { PICU stay }\end{array}$ \\
\hline Moller [28] & Bovactant & $\begin{array}{l}\text { Improved } \\
(+25 \% \\
\left.\mathrm{PaO}_{2} / \mathrm{FiO}_{2}\right)\end{array}$ & $\begin{array}{l}\text { Improved } \\
(-24 \%)^{\dagger}\end{array}$ & $\begin{array}{l}\text { Allowed less } \\
\text { aggressive } \\
\text { ventilation and } \\
\text { less rescue } \\
\text { therapies }\end{array}$ \\
\hline Yapicioglu [29] & Beractant & $\begin{array}{l}\text { Improved } \\
(-30 \% \mathrm{OI})\end{array}$ & $\begin{array}{l}\text { Improved } \\
(-21 \%)^{\dagger}\end{array}$ & $\begin{array}{l}\text { Less } \\
\text { aggressive } \\
\text { ventilation and } \\
\text { MOFS }\end{array}$ \\
\hline Willson $^{\circ}[30]$ & Calfactant & $\begin{array}{l}\text { Improved } \\
(-30 \% \mathrm{OI})\end{array}$ & $\begin{array}{l}\text { Improved } \\
(-17 \%)\end{array}$ & $\begin{array}{l}\text { Less rescue } \\
\text { therapies }\end{array}$ \\
\hline Thomas [31] & Lucinactant & $\begin{array}{l}\text { Improved } \\
(+25 \% \\
\left.\mathrm{PaO}_{2} / \mathrm{FiO}_{2}\right)\end{array}$ & Unchanged & $\begin{array}{l}\text { Shorter } \\
\text { ventilation in } \\
\text { less severe } \\
\text { cases }\end{array}$ \\
\hline Willson [32] & Calfactant & Unchanged & Unchanged & Unchanged \\
\hline Rodriguez-Moya* [33] & Surfacen & $\begin{array}{l}\text { Improved } \\
(-50 \% \mathrm{OI})\end{array}$ & Unchanged & $\begin{array}{l}\text { Improved } \\
\text { compliance } \\
\text { and chest } \\
\text { imaging }\end{array}$ \\
\hline Thomas [25] & Calfactant & Unchanged & Unchanged & Unchanged \\
\hline
\end{tabular}

Boxes were colored in green or red if, for a given outcome, the surfactant treatment had a positive effect or not, respectively. Boxes were left blank where no data were available. No studies reported any biochemical or biophysical parameter 


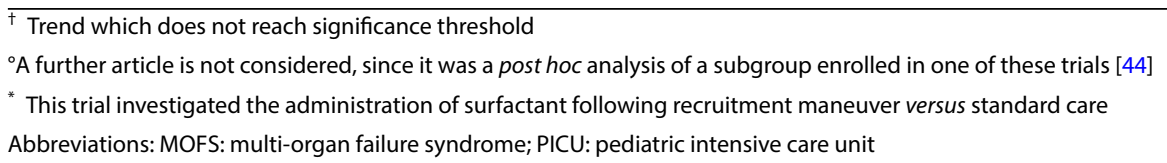

PARDS and NARDS. Studies should be performed according to the currently available PARDS and NARDS definitions and considering the more recent knowledge on ARDS pathobiology (strong agreement).

Nowadays, the availability of appropriate clinical definitions for PARDS and NARDS [1, 2] (Additional file 1) represents an important step forward to improve ARDS care and recognizes that differences exist between patients of various ages and severity. Few trials have used these definitions, and their implementation is urgently warranted. Although both the PALICC and the Berlin [45] definitions could be used for adolescents or young adults [3], it is advisable to prefer the pediatric definition to allow further comparison and data aggregation [3]. Some neonatal respiratory disorders that may appear as NARDS have been variously defined before the release of the Montreux definition of NARDS [1]. Nonetheless, pathophysiology and biology are shared between these disorders and the use of an unique definition can speed up research and development of surfactant therapies for a wider number of patients [1]. Knowledge of ARDS and surfactant pathobiology has significantly advanced during recent years, and new concepts have been introduced, such as the role of secretory phospholipase A2 enzymes in the surfactant catabolism $[11,46]$, the vicious cycle connecting surfactant catabolism and inflammation [17], the deficiency and injury of surfactant proteins [23, 47], the variable cellular injury in direct (primary) and indirect (secondary) ARDS [14, 16] and the lower susceptibility of infant and juvenile compared to adult lung tissue [9]. These concepts should be taken into account in future trial design.

2. PARDS and NARDS should be considered as syndromes and should be preclinically studied according to key characteristics, such as direct (primary) or indirect (secondary) nature, clinical severity, infectious or non-infectious origin or patients' age (strong agreement).

Several NARDS and PARDS experimental models are available to mimic these characteristics [48-51], but results of preclinical investigations cannot have the same value for all patients, since subtypes of PARDS and NARDS show relevant differences in pathobiology and pathophysiology. Several factors should be considered in pre-clinical models: trigger, animal size and the degree of lung development (i.e., patients' age), presence of immunodeficiency or comorbidities, as well as the initial severity and the ventilatory strategy $[1,8,52]$. Unfortunately, the need of different preclinical model to mimic different clinical situations has often gone unnoticed and may have negatively influenced the perception of research results. Accumulating data show that these factors significantly influence the clinical course and outcomes: thus it is important to consider them before starting a clinical trial [14, 16, 17, 53-55]. Lung size and the volume available for aeration are also important as they will influence surfactant volume of distribution, the actual alveolar delivery and consequently the optimal dose and administration method [56]. The type of surfactant preparation and its concentration must also be considered since the administered volume may significantly influence the amount of phospholipids actually reaching the alveoli [56]. For these reasons, there is a clear need of translational studies focused on at least some of these factors [57]. In this context, studies aiming to clarify the optimal surfactant concentration and dose to be administered are urgently needed.

2. Explanatory should be preferred over pragmatic design for future clinical trials on PARDS and NARDS (strong agreement).

This is the direct clinical counterpart of the previous point. ARDS is a very heterogeneous syndrome with various origins, presentations, severity, comorbidities and cointerventions. Trials enrolling broad groups of patients mixing all these factors are called pragmatic and seek a 'real-world' answer regarding an established intervention or refinement of current care [58]. This is not the case of surfactant and ARDS, since surfactant therapies are not yet standard of care for NARDS and PARDS and may represent a major improvement, rather than a minor refinement. Furthermore, although surfactant has a strong preclinical background suggesting its usefulness in ARDS, several concomitant clinical factors could influence response to treatment and outcomes $[14,16,17,53-$ 55]. Patients' age, type of ARDS, comorbidities, timing of the intervention, type and dose of surfactant, ventilatory policy and cointerventions are examples of the factors potentially important to stratify for. Trials with a highly 
Table 3 Synthesis of results: surfactant therapies in neonates

\begin{tabular}{|c|c|c|c|c|c|}
\hline Author/year & $\begin{array}{l}\text { Type of } \\
\text { surfactant }\end{array}$ & Oxygenation & $\begin{array}{l}\text { Biochemical } \\
\text { or } \\
\text { biophysical } \\
\text { parameters }\end{array}$ & Mortality & $\begin{array}{l}\text { Secondary } \\
\text { respiratory } \\
\text { outcomes }\end{array}$ \\
\hline \multicolumn{6}{|c|}{ Surfactant bolus } \\
\hline Lotze $^{\#}[34]$ & Beractant & n.a. & $\begin{array}{l}\text { Increased } \\
\text { SP-A } \\
(+300 \%)\end{array}$ & n.a. & $\begin{array}{l}\text { Shorter } \\
\text { ECMO, } \\
\text { Improved } \\
\text { compliance }\end{array}$ \\
\hline Findlay [35] & Beractant & $\begin{array}{l}\text { Improved } \\
(-78 \% \mathrm{OI})^{\dagger}\end{array}$ & n.a. & n.a. & $\begin{array}{l}\text { Shorter } \\
\text { ventilation, } \\
\text { oxygen } \\
\text { therapy and } \\
\text { NICU stay }\end{array}$ \\
\hline Lotze [36] & Beractant & n.a. & n.a. & n.a. & $\begin{array}{l}\text { Less need } \\
\text { for ECMO }\end{array}$ \\
\hline $\begin{array}{l}\text { Chinese group } \\
\text { [37] }\end{array}$ & Poractant- $\alpha$ & $\begin{array}{l}\text { Improved } \\
(-50 \% \mathrm{OI})^{\dagger}\end{array}$ & n.a. & n.a. & Unchanged \\
\hline Chang [38] & Kelisu & $\begin{array}{l}\text { Improved } \\
(-50 \% \mathrm{OI})\end{array}$ & n.a. & n.a. & $\begin{array}{l}\text { Shorter } \\
\text { ventilation }\end{array}$ \\
\hline Rong [43] & Kelisu & $\begin{array}{l}\text { Improved } \\
(-53 \% \mathrm{OI})\end{array}$ & n.a. & Unchanged & Unchanged \\
\hline \multicolumn{6}{|c|}{ Broncho-alveolar lavage with diluted surfactant } \\
\hline Wiswell [39] & Lucinactant & $(-67 \% \mathrm{OI})^{*}$ & n.a. & n.a. & Unchanged \\
\hline $\begin{array}{l}\text { Gadzinowski } \\
\text { [40] }\end{array}$ & Beractant & $\begin{array}{l}\text { Improved } \\
(-83 \% \mathrm{OI})\end{array}$ & n.a. & n.a. & Unchanged \\
\hline Dargaville [41] & Beractant & $(-54 \% \mathrm{OI})^{*}$ & n.a. & Improved ${ }^{\#}$ & $\begin{array}{l}\text { Less } \\
\text { aggressive } \\
\text { ventilation }\end{array}$ \\
\hline Bandiya [42] & Beractant & n.a. & n.a. & n.a. & $\begin{array}{l}\text { Shorter } \\
\text { ventilation } \\
\text { and } \mathrm{O}_{2} \\
\text { therapy@ }\end{array}$ \\
\hline
\end{tabular}


Table 3 (continued)

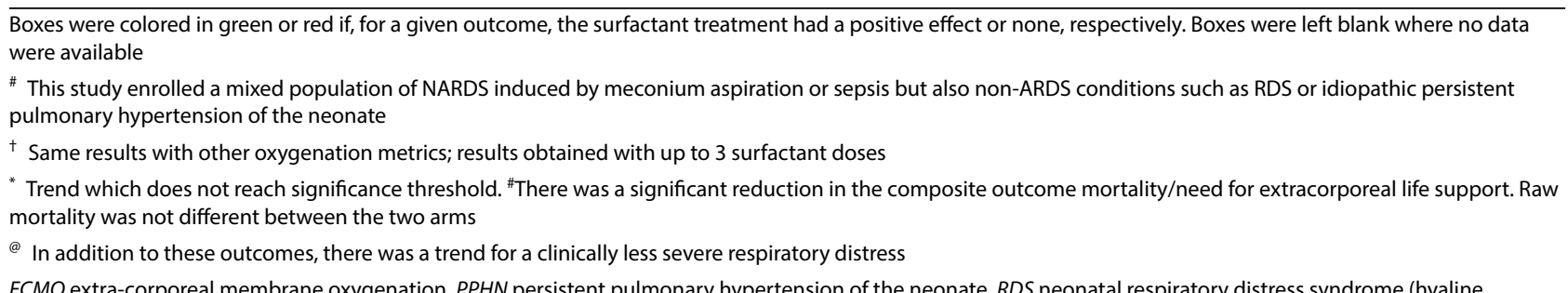
ECMO extra-corporeal membrane oxygenation, $P P H N$ persistent pulmonary hypertension of the neonate, RDS neonatal respiratory distress syndrome (hyaline membrane disease)

specific selection or stratification are called explanatory and are more suitable and likely to provide significant results, although they are more complex and long-lasting [58]. There are at least 10 items to be considered in order to evaluate the pragmatism of a trial design [59]. Thus, future clinical trials should be as more explanatory as possible and focus on homogeneous groups of patients, according to the recently accumulated knowledge. In the UK, such trials are termed 'efficacy and mechanism evaluation studies' as they allow experimental mechanism evaluation that is unhindered by predefined trial outcome measures [60]. The choice of an explanatory design reflects the complexity of PARDS and NARDS, the need to consider them as multifaceted syndromes and to learn from correspondent preclinical models. When it comes to PARDS, patients' age should also be restricted as much as possible, as it may significantly influence surfactant pharmacology and susceptibility to lung injury [9]. It is interesting to note that ventilation is the main co-intervention in these trials and was extremely variable and even non-protocolized in neonatal trials. This significantly reduces the trial quality and may have hindered the possibility to detect any effect of surfactant therapy.

A next step for a correct trial design would be a formal post hoc analysis of available data trying to identify which type of patients and ARDS should be the more likely to benefit from surfactant or which surfactant preparation should be preferred. According to a similar post hoc analysis of clinical trials conducted in adults [61] and to the recent knowledge on ARDS pathobiology and pharmacology [62], direct (primary) ARDS is more likely to benefit from surfactant treatments. In the future, we can imagine an even more individualized therapy by using genomic approaches or biomarkers of ARDS severity and type: the surfactant adsorption test [63-65] and the surfactant protein-D assay [66, 67] are two of the most advanced tools in this field. These, and other that may eventually come, can open the way for a precision medicine approach to ARDS surfactant therapy, as it is proposed in similar fields [68]. From a pharmacological point of view, preferably, an enhanced surfactant more resistant to phospholipase and inactivation has higher chances to be beneficial. A more concentrated surfactant seems also preferable, but the ideal dose and administration technique as well as the best strategy to spread it and increase alveolar delivery are still unknown and require specific studies.

4. Different clinical outcomes need to be chosen for PARDS and NARDS, according to the trial phase and design, type of trigger, severity class and/or surfactant treatment policy (strong agreement).

In general, trials must be conducted taking into consideration the most recent epidemiological data and a combination of clinically meaningful short- and long-term outcomes. For instance, it would be illogical to have mortality as a short-term outcome for mild PARDS or NARDS, as these are already subjected to relatively low mortality, while oxygenation, physiology parameters and burden of care measures are more suitable. As long-term outcomes, respiratory function measures may be preferred over pediatric quality of life measures which may be influenced by several other confounders [69].

Pathophysiological and biological plausibility is extremely important. Researchers should give priority to outcomes with a known direct pathophysiological link with the syndrome (such as short-term mortality, ventilator-free days and indices of gas exchange or oxygenation) [70-72]. Conversely, clinical endpoints that do not have a direct and clear connection with PARDS or NARDS should not be considered as primary outcomes. For instance, preterm neonates affected by NARDS may have negative long-term outcomes related to prematurity rather than to NARDS itself. Similarly, PARDS patients with malignancies may have a number of complications and negative outcomes because of their underlying disease rather than PARDS itself. Need for extracorporeal life support should only be considered if homogeneously available and defined in each recruiting center.

Finally, not only endpoints, but also the trajectory of disease should be considered in trial design. There are 
multiple benefits in doing so. For instance, oxygenation or ventilation metrics as well as lung mechanics parameters are repeated measures that lend themselves to multilevel (mixed effects) modeling. This will increase statistical power, which may be very important when studying particular populations in explanatory trials. This is also consistent with a personalized medicine approach as described above. Last but not least, multilevel modeling/trajectory analysis may adjust for the presence of other influencing factors such the availability of extracorporeal life support or other co-interventions.

\section{Discussion}

\section{Summary of the problem}

It is clear that the current perspective of surfactant therapies for PARDS and NARDS was biased by significant trial flaws as well as lack of cross-disciplinary awareness and knowledge of ARDS pathobiology. Despite the importance of this subject, there has not been any consensus statement so far. As a consequence, trials have been initiated by different investigators, mainly without industry support or regulatory agencies contribution and without a coordination strategy. Meanwhile biological knowledge on surfactant and ARDS was increasing. Research in this field is difficult and will still present practical and logistical issues; however, the four recommendations represent a helpful tool. In fact, a consensus statement is important to put the knowledge in perspective, increase cross-disciplinary awareness and avoid errors from the past.

It is important to recall the history that led to these errors: surfactant replacement for RDS was preclinically and clinically tested for the first time in 1972 and 1980, respectively [73, 74]. At that time, RDS and ARDS were considered the two forms of respiratory distress exclusively typical of neonates and adults. As time has passed, it became apparent that ARDS was also occurring in children [75]. Meanwhile, due to improvements in perinatal care, the limit of viability has decreased so infants with RDS were more and more premature. Soon it has been realized that not all neonates with RDS responded to surfactant replacement with similar effectiveness [76] and so the existence of NARDS had been hypothesized [77]. Finally, PARDS and NARDS have been officially recognized with age-specific definitions modeled on the Berlin criteria [3], although earlier ARDS definitions were also applied on children [78]. The first attempts to treat PARDS with surfactant have shortly followed the enthusiasm of pediatricians using surfactant for $\operatorname{RDS}[79,80]$. Similarly, surfactant administration was tried for a number of neonatal 'ARDS-like' disorders (such as meconium aspiration syndrome, pneumonia, sepsis-related respiratory failure) [76]. However, these studies have been performed without: (1) clear definition of PARDS and NARDS, (2) key concepts of pathobiology and (3) clear drug development pathway.

\section{Clinical implications of biological research}

Exogenous surfactant may be quickly inactivated and/ or damaged by phospholipases: [81] commercially available surfactants do not contain crucial molecules providing anti-inflammatory or phospholipase-inhibitory activity, such as surfactant protein-A and -D or dioleoylphosphatidylglycerol (DOPG), and this may obviously reduce their efficacy $[82,83]$. Club Cell secretory protein [84], human-recombinant surfactant protein-D [85], Nf-KB pathway inhibitors [86], DOPG [87] and varespladib $[88,89]$ are only some example of drugs that might fill this gap, protect surfactant and enhance its activity, while decreasing inflammation. Surfactants engineered to be more resistant to inactivation might also achieve the same objectives. While these molecules have not yet reached clinical use, it is not surprising that budesonide, a well-known synthetic steroid, had been administered using surfactant as carrier. This gave promising results in neonates with NARDS [90]. Also, budesonide decreases the expression of secretory phospholipase A2 [91] and has a clinically significant anti-inflammatory effect in preterm neonates at risk of broncho-pulmonary dysplasia [92]. Other surfactant-injuring agents have been well characterized in ARDS patients, and surfactant replacement might at least partially counterbalance the reduction of endogenous surfactant biophysical activity [23]. This could be measured at the bedside to personalize the dosing $[47,64]$. In time, our knowledge about exogenous surfactant has increased and now we know that not all surfactant preparations are equal. Phospholipid profile and protein content are important for the clinical efficacy in neonates with RDS [26, 93], and it is likely that these characteristics would be relevant also in patients with PARDS and NARDS [23].

\section{Accuracy and difficulty of clinical trials design}

Surfactant trials in PARDS and NARDS have not followed a clear drug development pathway, so far. Dose ranging trials are still lacking due to bias in funding allegedly 'definitive studies.' This is likely the main difficulty to design the adequate clinical trial. Others factors to be accurately considered are lung size and aeration, presence of phospholipases and other surfactant-injuring agents, timing of administration, ventilatory policy, resistance of surfactant to inactivation and presence of molecules enhancing its activity [88, 89, 94, 95]. Moreover, surfactant delivery is a complex physical phenomenon: any viscous fluid flowing over a surface leaves a coating film that increases in thickness as shear viscosity increases. 
Coating the conducting airways significantly reduces the amount of instilled surfactant really reaching the alveoli (i.e., the 'coating cost'): the instilled volumes must be above the coating cost to deliver sufficient surfactant to the alveoli, and modeling studies show that surfactant doses trialed so far have overcome the coating cost only for neonates, but not for older patients [56]. This issue is extremely important, since too low doses may lack of efficacy, but too high doses may theoretically affect lung tissue inflammation and antibacterial defenses [96, 97].

Surfactant trials published so far have also quite different key features, and this made data aggregation difficult, especially for pediatric patients. Only recently, a multicenter study led to definition of sharing criteria to administer surfactant in PARDS as compassionate therapy [98]. Currently ongoing explanatory trials recruit homogeneous populations of infants with bronchiolitis-induced PARDS $[60,99]$. These are examples of a correct step on the drug development pathway for a particular subgroup of patients.

The administration technique should also be deeply studied in order to ensure the best alveolar delivery. Bolus or broncho-alveolar lavage with diluted surfactant solutions may be used: the latter might be particularly efficacious in direct (primary) PARDS and NARDS [100, 101]. However, the technique is invasive and optimized surfactant bolus might provide equally significant benefits at least in some cases.

An adequate clinical research project should be based on recent pathobiology concepts and should start from finding the best dose and administration schedule/technique. Then, a trial enrolling direct (primary) PARDS or NARDS should be designed targeting meaningful clinical outcomes but also physiopathological and/or biological or biophysical measures. Enrolled patients should be as more homogeneous as possible, not only for the ARDS type but also for the other aforementioned factors.

\section{Conclusions}

We advocate for well-designed preclinical and explanatory clinical studies to investigate the use of surfactant for PARDS and NARDS. Given the accumulating knowledge on ARDS biology, it is likely that surfactant therapies might be beneficial for PARDS and NARDS. Moreover, there is wide room for improving these therapies with the addition of drugs enhancing surfactant activity and/ or reducing lung inflammation. It is also likely that previous inconsistent results would have been due to our lack of knowledge and misleading study designs. This field is an example of how preclinical knowledge can inform the clinical research pathway and how explanatory trials are needed to prevent losing promising therapies.

\section{Supplementary Information}

The online version contains supplementary material available at https://doi. org/10.1186/s13054-021-03489-6.

Additional file 1. PARDS AND NARDS Definitions

Additional file 2. METHODS - Methods for literature review protocol and consensus methodology)

Additional file 3. ADDITIONAL RESULTS - Basic data of clinical trials

\section{Abbreviations}

ARDS: Acute respiratory distress syndrome; DOPG: Dioleoyl-phosphatidylglycerol; ECMO: Extra-Corporeal Membrane Oxygenation; MOFS: Multi-organ failure syndrome; NARDS: Neonatal acute respiratory distress syndrome; PALICC: Pediatric acute lung injury consensus conference; PARDS: Pediatric acute respiratory distress syndrome; PICU: Pediatric intensive care unit; PL: Phospholipids; RAND/UCLA: Research and Development/University of California, Los Angeles; RDS: Respiratory distress syndrome.

\section{Acknowledgements}

Authors are grateful to Alejandro Alonso (PhD) for preparing the graphical abstract. Authors also wish to thank Prof. Sushma Nangia, Prof. Thomas Wiswell and Prof. Bo Sun for providing important informations about their manuscripts. PT is the ESPNIC President, DDL is the ESPNIC President Elect, MCK is the ESPNIC Chair of Scientific Affairs, PB and PR are ESPNIC Past-Presidents.

\section{Authors' contributions}

DDL wrote the manuscript draft and extracted data from clinical trials and took care of the consensus methodology. PC contributed to the data interpretation, provided pre-clinical and clinical expertise and critically reviewed the manuscript for important intellectual content. MCK took care of the consensus methodology, provided clinical expertise and critically reviewed the manuscript for important intellectual content. PB provided clinical expertise and critically reviewed the manuscript for important intellectual content. MGS provided clinical expertise, helped to interpret the data and critically reviewed the manuscript for important intellectual content. JPG provided pre-clinical expertise, helped to interpret the data and critically reviewed the manuscript for important intellectual content. GC provided clinical expertise and critically reviewed the manuscript for important intellectual content. PT provided pre-clinical and clinical expertise, helped to interpret the data and critically reviewed the manuscript for important intellectual content. PR supervised the whole project, provided clinical expertise, helped to interpret the data and critically reviewed the manuscript for important intellectual content. All authors read and approved the final manuscript.

\section{Funding}

None.

Availability of data and materials

All data generated or analyzed during this study are included in this published article and its supplementary information files.

Ethical approval and consent to participate Not applicable.

\section{Consent for publication \\ Not applicable.}

\section{Competing interests}

DDL received research and educational grants from Chiesi Pharmaceuticals spa and ABBVIE inc. He served as lecturer for, Chiesi Pharmaceuticals spa, ABBVIE inc and Getinge, and finally, has been a member of advisory boards for Chiesi Pharmaceuticals spa, ABBVIE inc, Airway Therapeutics and a consultant for OPHIREX inc. PC received research and educational grants and has been a member of advisory board for Chiesi Pharmaceuticals spa. MCK received research and educational grants from Vyaire. He served as a consultant and lecturer for Vyaire. Finally, MK has received research funding from The Royal Dutch Academy of Sciences, ZonMW, NHLBI/NIH and Stichting Vrienden Beatrix Kinderziekenhuis. PB served as lecturer for Chiesi Pharmaceutical spa 
and Getinge. He received research grants from and has been a member of advisory board for Chiesi Pharmaceuticals spa. MGS has been a member of advisory board for Chiesi Pharmaceuticals spa. JPG received research grants and assistance and/or served as consultant for Chiesi Pharmaceuticals spa, CENSA and Airway Therapeutics. GC served as lecturer and advisory board member for Chiesi Pharmaceuticals spa. PT has received research grants from and has been an advisory board member for Chiesi Pharmaceuticals spa. He received research grant from BioMérieux Inc. and has been serving as consultant for Sedana Inc., Baxter Acute Therapies Inc., and Bristol Myers Squib Inc. PCR has no conflict of interest to declare.

\section{Author details}

${ }^{1}$ Division of Pediatrics and Neonatal Critical Care, "A.Béclère" Medical Centre, Paris Saclay University Hospitals, APHP, 157 Rue de la Porte de Trivaux, 92140 Clamart (Paris-IDF), France. ${ }^{2}$ Physiopathology and Therapeutic Innovation Unit-INSERM U999, Paris Saclay University, Paris, France. ${ }^{3}$ Department of Pediatrics, University of Udine, Udine, Italy. ${ }^{4}$ Division of Pediatric Critical Care Medicine, Department of Pediatrics, Beatrix Children's Hospital Groningen, University Medical Centre Groningen, University of Groningen, Groningen, The Netherlands. ${ }^{5}$ Critical Care, Anesthesiology, Peri-Operative and Emergency Medicine (CAPE), University of Groningen, Groningen, The Netherlands. ${ }^{6}$ Department of Neonatal and Pediatric Critical Care, Azienda Ospedaliera Universitaria Integrata Verona, Verona, Italy. ${ }^{7}$ Health Protection Research Unit in Emerging and Zoonotic Infections, Department of Clinical Infection, Microbiology and Immunology, University of Liverpool, Liverpool, UK. ${ }^{8}$ Department of Biochemistry and Molecular Biology and Research Institute "Hospital 12 de Octubre", Complutense University, Madrid, Spain. ${ }^{9}$ Department of Anesthesiology and Intensive Care, Catholic University of the Sacred Heart, Rome, Italy. ${ }^{10}$ Division of Pediatric Critical Care and Neonatal Medicine, "Kremlin-Bicetre" Medical Center, Paris Saclay University Hospitals, APHP, Paris, France. ${ }^{11}$ Integrative Cellular Biology Institute-UMR 9198, Host-Pathogen Interactions Team, Paris Saclay University, Paris, France. ${ }^{12}$ Division of Neonatology and Pediatric Critical Care, Department of Pediatrics, University Hospital of Geneva, University of Geneva, Geneva, Switzerland.

Received: 25 December 2020 Accepted: 4 February 2021 Published online: 22 February 2021

\section{References}

1. De Luca D, van Kaam AH, Tingay DG, Courtney SE, Danhaive O, Carnielli VP, et al. The Montreux definition of neonatal ARDS: biological and clinical background behind the description of a new entity. Lancet Respir Med. 2017;5:657-66.

2. Khemani RG, Smith LS, Zimmerman JJ, Erickson S. Pediatric acute respiratory distress syndrome: definition, incidence, and epidemiology. Pediatr Crit Care Med. 2015;16:S23-40.

3. De Luca D. Personalising care of acute respiratory distress syndrome according to patients'age. Lancet Respir Med. 2019;7:100-1.

4. Aggarwal NR, King LS, D'Alessio FR. Diverse macrophage populations mediate acute lung inflammation and resolution. Am J Physiol Lung Cell Mol Physiol. 2014;306:L709-25.

5. Millar FR, Summers C, Griffiths MJ, Toshner MR, Proudfoot AG. The pulmonary endothelium in acute respiratory distress syndrome: insights and therapeutic opportunities. Thorax. 2016;71:462-73.

6. Raghavendran K, Willson D, Notter RH. Surfactant therapy for acute lung injury and acute respiratory distress syndrome. Crit Care Clin. 2011;27:525-59.

7. De Luca D, Piastra M, Chidini G, Tissieres P, Calderini E, et al. On behalf of Respiratory Section of the European Society for Pediatric Neonatal Intensive Care (ESPNIC). The use of the Berlin definition for acute respiratory distress syndrome during infancy and early childhood: multicenter evaluation and expert consensus. Intensive Care Med. 2013;39:2083-91.

8. Khemani RG. Khemani RG, Smith L, Lopez-Fernandez YM, Kwok J, Morzov R, Klein MJ, et al. Pediatric Acute Respiratory Distress syndrome Incidence and Epidemiology (PARDIE) Investigators; Pediatric Acute Lung Injury and Sepsis Investigators (PALISI) Network. Paediatric acute respiratory distress syndrome incidence and epidemiology (PARDIE): an international, observational study. Lancet Respir Med. 2019;7:115-128.
Erratum in: Lancet Respir Med. 2018 Nov 13: Erratum in: Lancet Respir Med. 2019;7:e12.

9. Kneyber MCJ, Zhang H, Slutsky AS. Ventilator-induced lung injury: similarity and differences between children and adults. Am J Respir Crit Care Med. 2014;190:258-65.

10. Günther A, Ruppert C, Schmidt R, Markart P, Grimminger F, Walmrath D, et al. Surfactant alteration and replacement in acute respiratory distress syndrome. Respir Res. 2001;2:353-64.

11. De Luca D, Lopez-Rodriguez E, Minucci A, Vendittelli F, Gentile L, Stival E, et al. Clinical and biological role of secretory phospholipase A2 in acute respiratory distress syndrome infants. Crit Care. 2013;17:R163.

12. Touqui $L$, Arbibe $L$. A role for phospholipase $A 2$ in ARDS pathogenesis. Mol Med Today. 1999;5:244-9.

13. Cogo PE, Toffolo GM, Ori C, Vianello A, Chierici M, Gucciardi A, et al. Surfactant disaturated-phosphatidylcholine kinetics in acute respiratory distress syndrome by stable isotopes and a two-compartment model. Respir Res. 2007;8:13.

14. Calfee CS, Janz DR, Bernard GR, May AK, Kangelaris KN, Matthay MA, et al. Distinct molecular phenotypes of direct vs indirect ARDS in singlecenter and multicenter studies. Chest. 2015;147:1539-48.

15. Moussa MD, Santonocito C, Fagnoul D, Donadello K, Pradier O, Gaussem $P$, et al. Evaluation of endothelial damage in sepsis-related ARDS using circulating endothelial cells. Intensive Care Med. 2015;41:231-8.

16. Calfee CS, Delucchi K, Parsons PE, Thompson BT, Ware LB, Matthay MA. Subphenotypes in acute respiratory distress syndrome: latent class analysis of data from two randomised controlled trials. Lancet Respir Med. 2014;2:611-20.

17. Yehya N, Keim G, Thomas NJ. Subtypes of pediatric acute respiratory distress syndrome have different predictors of mortality. Intensive Care Med. 2018;44:1230-9.

18. Santhakumaran S, Gordon A, Prevost AT, O'Kane C, McAuley DF, Shankar-Hari M. Heterogeneity of treatment effect by baseline risk of mortality in critically ill patients: re-analysis of three recent sepsis and ARDS randomised controlled trials. Crit Care. 2019;23:156.

19. Shankar-Hari M, Rubenfeld GD. Population enrichment for critical care trials: phenotypes and differential outcomes. Curr Opin Crit Care. 2019;25:489-97.

20. Tamburro RF, Kneyber MCJ. Pulmonary specific ancillary treatment for pediatric acute respiratory distress syndrome: proceedings from the pediatric acute lung injury consensus conference. Pediatr Crit Care Med. 2015;16:S61-72.

21. Kneyber MCJ, de Luca D, Calderini E, Jarreau P-H, Javouhey E, et al. on behalf of the section Respiratory Failure of the European Society for Paediatric and Neonatal Intensive Care. Recommendations for mechanical ventilation of critically ill children from the Paediatric Mechanical Ventilation Consensus Conference (PEMVECC). Intensive Care Med. 2017;43:1764-80.

22. Ardell S, Pfister RH, Soll R. Animal derived surfactant extract versus protein free synthetic surfactant for the prevention and treatment of respiratory distress syndrome. Cochrane Database Syst Rev. 2015;(5):CD000144.

23. Echaide M, Autilio C, Arroyo R, Perez-Gil J. Restoring pulmonary surfactant membranes and films at the respiratory surface. Biochim Biophys Acta Biomembr. 2017;1859(9 Pt B):1725-1739.

24. Quaker Foundations of Leadership. A comparison of Quaker-based consensus and Robert's rules of order. Richmond (VI) USA: Earlham College; 1999.

25. Thomas NJ, Spear D, Wasserman E, Pon S, Markovitz B, Singh AR, et al. CALIPSO: a randomized controlled trial of calfactant for acute lung injury in pediatric stem cell and oncology patients. Biol Blood Marrow Transplant. 2018;24:2479-86.

26. Tridente A, De Martino L, De Luca D. Porcine vs bovine surfactant therapy for preterm neonates with RDS: systematic review with biological plausibility and pragmatic meta-analysis of respiratory outcomes. Respir Res. 2019;20(1):28.

27. Willson DF, Zaritsky A, Bauman LA, Dockery K, James RL, Conrad D, et al. Instillation of calf lung surfactant extract (calfactant) is beneficial in pediatric acute hypoxemic respiratory failure. Crit Care Med. 1999;27:188-95.

28. Möller JC, Schaible T, Roll C, Schiffmann J-H, Bindl L, Schrod L, et al. Treatment with bovine surfactant in severe acute respiratory distress 
syndrome in children: a randomized multicenter study. Intensive Care Med. 2003;29:437-46.

29. Yapıcıoğlu H, Yıldızdaş D, Bayram I, Sertdemir Y, Yılmaz HL. The use of surfactant in children with acute respiratory distress syndrome: efficacy in terms of oxygenation, ventilation and mortality. Pulm Pharm Ther. 2003;16:327-33.

30. Willson DF, Thomas NJ, Markovitz BP, Bauman LA, DiCarlo JV, Pon S, et al. Effect of exogenous surfactant (calfactant) in pediatric acute lung injury: a randomized controlled trial. JAMA. 2005;293:470-6.

31. Thomas NJ, Guardia CG, Moya FR, Cheifetz IM, Markovitz B, Cruces $P$, et al. A pilot, randomized, controlled clinical trial of lucinactant, a peptide-containing synthetic surfactant, in infants with acute hypoxemic respiratory failure. Pediatr Crit Care Med. 2012;13:646-53.

32. Willson DF, Thomas NJ, Tamburro R, Truemper E, Truwit J, Conaway M, et al. Pediatric calfactant in acute respiratory distress syndrome trial. Pediatr Crit Care Med. 2013;14:657-65.

33. Rodríguez-Moya VS, Gallo-Borrero CM, Santos-Áreas D, Prince-Martínez IA, Díaz-Casañas E, López-Herce CJ. Exogenous surfactant and alveolar recruitment in the treatment of the acute respiratory distress syndrome: Treatment of the ARDS. Clin Resp J. 2017;11:1032-9.

34. Lotze A, Knight GR, Martin GR, Bulas DI, Hull WM, O'Donnell RM, et al. Improved pulmonary outcome after exogenous surfactant therapy for respiratory failure in term infants requiring extracorporeal membrane oxygenation. J Pediatr. 1993;122:261-8.

35. Findlay RD, Taeusch HW, Walther FJ. Surfactant replacement therapy for meconium aspiration syndrome. Pediatrics. 1996;97:48-52.

36. Lotze A, Mitchell BR, Bulas DI, Zola EM, Shalwitz RA, Gunkel JH. Multicenter study of surfactant (beractant) use in the treatment of term infants with severe respiratory failure. Survanta in Term Infants Study Group. J Pediatr. 1998;132:40-7.

37. Chinese Collaborative Study Group for Neonatal Respiratory Diseases. Treatment of severe meconium aspiration syndrome with porcine surfactant: a multicentre, randomized, controlled trial. Acta Paediatr. 2005;94:896-902.

38. Chang M, Lu H-Y, Xiang H, Lan H-P. Clinical effects of different ways of mechanical ventilation combined with pulmonary surfactant in treatment of acute lung injury/acute respiratory distress syndrome in neonates: a comparative analysis. Chin J Contemp Pediatr. 2016;18:1069-74.

39. Wiswell TE, Knight GR, Finer NN, Donn SM, Desai H, Walsh WF, et al. A multicenter, randomized, controlled trial comparing surfaxin (lucinactant) lavage with standard care for treatment of meconium aspiration syndrome. Pediatrics. 2002;109:1081-7.

40. Gadzinowski J, Kowalska K, Vidyasagar D. Treatment of MAS with PPHN using combined therapy: SLL, bolus surfactant and iNO. J Perinatol. 2008;28:S56-66.

41. Dargaville PA, Copnell B, Mills JF, Haron I, Lee JKF, Tingay DG, et al. Randomized controlled trial of lung lavage with dilute surfactant for meconium aspiration syndrome. J Pediatr. 2011;158:383-9.

42. Bandiya P, Nangia S, Saili A. Surfactant lung lavage vs. standard care in the treatment of meconium aspiration syndrome: a randomized trial. J Trop Pediatr. 2019;65:114-21.

43. Rong Z, Mo L, Pan R, Zhu X, Cheng H, Li M, et al. Bovine surfactant in the treatment of pneumonia-induced-neonatal acute respiratory distress syndrome (NARDS) in neonates beyond 34 weeks of gestation: a multicentre, randomized, assessor-blinded, placebo-controlled trial. Eur J Pediatr. 2020 Oct 21:1-9. doi: https://doi.org/10.1007/s00431-02003821-2. Epub ahead of print.

44. Tamburro RF, Thomas NJ, Pon S, Jacobs BR, DiCarlo JV, Markovitz BP, et al. Post hoc analysis of calfactant use in immunocompromised children with acute lung injury: Impact and feasibility of further clinical trials. Pediatr Crit Care Med. 2008;9:459-64.

45. ARDS Definition Task Force, Ranieri VM, Rubenfeld GD, Thompson BT, Ferguson ND, Caldwell E, Fan E, Camporota L, Slutsky AS. Acute respiratory distress syndrome: the Berlin Definition. JAMA. 2012;307(23):2526-33.

46. De Luca D, Shankar-Aguilera S, Autilio C, Raschetti R, Vedovelli L, Fitting C, et al. Surfactant-secreted phospholipase A 2 interplay and respiratory outcome in preterm neonates. Am J Physiol Lung Cell Mol Physiol. 2020;319:L95-104.
47. Autilio C, Echaide M, Shankar-Aguilera S, Bragado R, Amidani D, Salomone $F$, et al. Surfactant injury in the early phase of severe meconium aspiration syndrome. Am J Respir Cell Mol Biol. 2020;63:327-37.

48. Spengler D, Rintz N, Krause MF. An Unsettled Promise: The Newborn Piglet Model of Neonatal Acute Respiratory Distress Syndrome (NARDS). Physiologic Data and Systematic Review. Front Physiol. 2019;10:1345.

49. Ballard-Croft C, Wang D, Sumpter LR, Zhou X, Zwischenberger JB. Largeanimal models of acute respiratory distress syndrome. Ann Thorac Surg. 2012;93:1331-9.

50. Yehya N. Lessons learned in acute respiratory distress syndrome from the animal laboratory. Ann Transl Med. 2019;7:503-503.

51. Elsayed YN, Hinton M, Graham R, Dakshinamurti S. Lung ultrasound predicts histological lung injury in a neonatal model of acute respiratory distress syndrome. Pediatr Pulmonol. 2020;55:2913-23.

52. Randolph AG. Management of acute lung injury and acute respiratory distress syndrome in children. Crit Care Med. 2009;37:2448-54.

53. Bindl L, Buderus S, Dahlem P, Demirakca S, Goldner M, Huth R, et al. Gender-based differences in children with sepsis and ARDS: The ESPNIC ARDS Database Group. Intensive Care Med. 2003;29:1770-3.

54. Luo L, Shaver CM, Zhao Z, Koyama T, Calfee CS, Bastarache JA, et al. Clinical predictors of hospital mortality differ between direct and indirect ARDS. Chest. 2017;151:755-63.

55. Wong JJ-M, Phan HP, Phumeetham S, Ong JSM, Chor YK, Qian S, et al. Risk stratification in pediatric acute respiratory distress syndrome: a multicenter observational study. Crit Care Med. 2017;45:1820-8.

56. Grotberg JB, Filoche M, Willson DF, Raghavendran K, Notter RH. Did reduced alveolar delivery of surfactant contribute to negative results in adults with acute respiratory distress syndrome? Am J Resp Crit Care Med. 2017;195:538-40.

57. Sinha P, Calfee CS. Phenotypes in acute respiratory distress syndrome: moving towards precision medicine. Curr Opin Crit Care. 2019;25:12-20

58. De Luca D, Harrison DA, Peters MJ. 'Lumping or splitting' in paediatric acute respiratory distress syndrome (PARDS). Intensive Care Med. 2018;44:1548-50.

59. Thorpe $K E$, Zwarenstein $M, O x m a n A D$, Treweek $S$, Furberg $C D$, Altman $D G$, et al. A pragmatic-explanatory continuum indicator summary (PRECIS): a tool to help trial designers. J Clin Epidemiol. 2009;62:464-75.

60. The bronchiolitis endotracheal surfactant study (BESS) [Internet]. Available from: http://www.isrctn.com/ISRCTN1 1746266. Accessed on January 22, 2021

61. Taut FJH, Rippin G, Schenk P, Findlay G, Wurst W, Häfner D, et al. A search for subgroups of patients with ARDS who may benefit from surfactant replacement therapy. Chest. 2008;134:724-32.

62. De Luca D, Piastra M, Tosi F, Pulitano S, Mancino A, Genovese O, et al. Pharmacological therapies for pediatric and neonatal ALI/ARDS: an evidence-based review. Curr Drug Targets. 2012;13:906-16.

63. De Luca D, Vázquez-Sánchez S, Minucci A, Echaide M, Piastra M, Conti $\mathrm{G}$, et al. Effect of whole body hypothermia on inflammation and surfactant function in asphyxiated neonates. Eur Resp J. 2014;44:1708-10.

64. Ravasio A, Cruz A, Pérez-Gil J, Haller T. High-throughput evaluation of pulmonary surfactant adsorption and surface film formation. J Lipid Res. 2008;49:2479-88.

65. Autilio C, Echaide M, Benachi A, Marfaing-Koka A, Capoluongo ED, Pérez-Gil J, et al. A noninvasive surfactant adsorption test predicting the need for surfactant therapy in preterm infants treated with continuous positive airway pressure. J Pediatr. 2017;182:66-73.

66. Dahmer MK, Flori H, Sapru A, Kohne J, Weeks HM, Curley MAQ, et al. Surfactant Protein $D$ is associated with severe pediatric ARDS, prolonged ventilation, and death in children with acute respiratory failure. Chest. 2020;158:1027-35.

67. Ward SL, Dahmer MK, Weeks HM, Sapru A, Quasney MW, Curley MAQ, et al. Association of patient weight status with plasma surfactant protein $\mathrm{D}$, a biomarker of alveolar epithelial injury, in children with acute respiratory failure. Pediatr Pulmonol. 2020;55:2730-6.

68. De Luca D, Autilio C, Pezza L, Shankar-Aguilera S, Tingay D, Carnielli V. Personalised medicine for the management of RDS in preterm neonates. Neonatology. 2021 in press;

69. Germain N, Aballéa S, Toumi M. Measuring health-related quality of life in young children: how far have we come? J Mark Access Health Policy. 2019;22:7:1618661. Erratum in: J Mark Access Health Policy. 2019;7:1626572. 
70. Weed DL, Hursting SD. Biologic plausibility in causal inference: current method and practice. Am J Epidemiol. 1998;147:415-25.

71. Fedak KM, Bernal A, Capshaw ZA, Gross S. Applying the Bradford Hill criteria in the 21st century: how data integration has changed causal inference in molecular epidemiology. Emerg Themes Epidemiol. 2015;12:14.

72. Contentin L, Ehrmann S, Giraudeau B. Heterogeneity in the definition of mechanical ventilation duration and ventilator-free days. Am J Resp Crit Care Med. 2014:189:998-1002.

73. Enhörning $G$, Robertson B. Lung expansion in the premature rabbit fetus after tracheal deposition of surfactant. Pediatrics. 1972:50:58-66.

74. Fujiwara T, Maeta H, Chida S, Morita T, Watabe Y, Abe T. Artificial surfactant therapy in hyaline-membrane disease. Lancet. 1980;1:55-9.

75. Newth CJ, Stretton M, Deakers TW, Hammer J. Assessment of pulmonary function in the early phase of ARDS in pediatric patients. Pediatr Pulmonol. 1997:23:169-75.

76. Wirbelauer J, Speer CP. The role of surfactant treatment in preterm infants and term newborns with acute respiratory distress syndrome. J Perinatol. 2009;29(Suppl 2):S18-22.

77. Faix RG, Viscardi RM, DiPietro MA, Nicks JJ. Adult respiratory distress syndrome in full-term newborns. Pediatrics. 1989;83:971-6.

78. Ashbaugh DG, Boyd Bigelow D, Petty TL, Levine BE. Acute respiratory distress in adults. Lancet. 1967;290:319-23.

79. Lachmann B. Animal models and clinical pilot studies of surfactant replacement in adult respiratory distress syndrome. Eur Respir J Suppl. 1989;3:98s-103s.

80. Marraro G. Use of surfactant in respiratory diseases in neonates and infants. Cah Anesthesiol. 1994;42:159-66 [article in French].

81. Kitsiouli E, Nakos G, Lekka ME. Phospholipase A2 subclasses in acute respiratory distress syndrome. Biochim Biophys Acta. 2009:1792(10):941-53.

82. Arbibe L, Koumanov K, Vial D, Rougeot C, Faure G, Havet N, et al. Generation of lyso-phospholipids from surfactant in acute lung injury is mediated by type-II phospholipase A2 and inhibited by a direct surfactant protein A-phospholipase A2 protein interaction. J Clin Invest. 1998;102:1152-60.

83. Berger A, Havet N, Vial D, Arbibe L, Dumarey C, Watson ML, et al. Dioleylphosphatidylglycerol inhibits the expression of type II phospholipase A2 in macrophages. Am J Respir Crit Care Med. 1999;159:613-8.

84. Pilon AL. Rationale for the development of recombinant Human CC10 as a therapeutic for inflammatory and fibrotic disease. Ann N Y Acad Sci. 2000:923:280-99.

85. Kishore U, Bernal AL, Kamran MF, Saxena S, Singh M, Sarma PU, et al. Surfactant proteins SP-A and SP-D in human health and disease. Arch Immunol Ther Exp (Warsz). 2005;53:399-417.

86. von Bismarck P, Klemm K, García Wistädt C-F, Winoto-Morbach S, Schütze S, Krause MF. Selective NF-kB inhibition, but not dexamethasone, decreases acute lung injury in a newborn piglet airway inflammation model. Pulm Pharm Ther. 2009:22:297-304.

87. Preuß S, Scheiermann J, Stadelmann S, Omam FD, Winoto-Morbach S, Lex D, et al. 18:1/18:1-Dioleoyl-phosphatidylglycerol prevents alveolar epithelial apoptosis and profibrotic stimulus in a neonatal piglet model of acute respiratory distress syndrome. Pulm Pharm Ther. 2014:28:25-34.

88. De Luca D, Minucci A, Trias J, Tripodi D, Conti G, Zuppi C, et al. Varespladib inhibits secretory phospholipase A2 in bronchoalveolar lavage of different types of neonatal lung injury. J Clin Pharmacol. 2012;52:729-37.

89. De Luca D, Minucci A, Piastra M, Cogo PE, Vendittelli F, Marzano L, et al. Ex vivo effect of varespladib on secretory phospholipase A2 Alveolar activity in infants with ARDS. PLOS ONE. 2012;7:e47066.

90. Deliloglu B, Tuzun F, Cengiz MM, Ozkan H, Duman N. Endotracheal surfactant combined with budesonide for neonatal ARDS. Front Pediatr. 2020;8:210.

91. Triggiani M, Granata F, Petraroli A, Loffredo S, Frattini A, Staiano RI, et al. Inhibition of secretory phospholipase A2-induced cytokine production in human lung macrophages by budesonide. Int Arch Allergy Immunol. 2009;150:144-55.

92. Venkataraman R, Kamaluddeen M, Hasan SU, Robertson HL, Lodha A. Intratracheal administration of budesonide-surfactant in prevention of bronchopulmonary dysplasia in very low birth weight infants: a systematic review and meta-analysis. Pediatr Pulmonol. 2017:52:968-75.

93. Foligno S, De Luca D. Porcine versus bovine surfactant therapy for RDS in preterm neonates: pragmatic meta-analysis and review of physiopathological plausibility of the effects on extra-pulmonary outcomes. Respir Res. 2020;21(1):8.

94. Cogo PE, Facco M, Simonato M, Verlato G, Rondina C, Baritussio A, et al. Dosing of porcine surfactant: effect on kinetics and gas exchange in respiratory distress syndrome. Pediatrics. 2009;124:e950-7.

95. Cogo PE, Facco M, Simonato M, De Luca D, De Terlizi F, Rizzotti U, et al. Pharmacokinetics and clinical predictors of surfactant redosing in respiratory distress syndrome. Intensive Care Med. 2011;37:510-7.

96. Sun Y, Wang Y-Q, Yang R, Zhu J-J, Le Y-Y, Zhong J-G, et al. Exogenous porcine surfactants increase the infiltration of leukocytes in the lung of rats. Pulm Pharm Ther. 2009;22:253-9.

97. Schrod L, Hornemann F, von Stockhausen HB. Chemiluminescence activity of phagocytes from tracheal aspirates of premature infants after surfactant therapy. Acta Paediatr. 1996;85:719-23.

98. Wolfler A, Piastra M, Amigoni A, Santuz P, Gitto E, Rossetti E, et al. A shared protocol for porcine surfactant use in pediatric acute respiratory distress syndrome: a feasibility study. BMC Pediatr. 2019;19:203.

99. Biban P, Conti G, Wolfler AM, Carlassara S, Gitto E, Rulli I, et al. Efficacy and safety of exogenous surfactant therapy in patients under 12 months of age invasively ventilated for severe bronchiolitis (SURFAB$\mathrm{RON}$ ): protocol for a multicentre, randomised, double-blind, controlled, non-profit trial. BMJ Open. 2020;10:e038780.

100. Choi HJ, Hahn S, Lee J, Park B-J, Lee SM, Kim H-S, et al. Surfactant LAVAGE THERAPY FOR MECONIUM ASPIRATION SYNDROME: A SYSTEMATIC REVIEW AND META-ANALYSIS. Neonatology. 2012;101:183-91.

101. Henn R, Fiori RM, Fiori HH, Pereira MR, Colvero MO, Ramos Garcia $P C$, et al. Surfactant with and without bronchoalveolar lavage in an experimental model of meconium aspiration syndrome. J Perinat Med. 2016:44:685-9.

\section{Publisher's Note}

Springer Nature remains neutral with regard to jurisdictional claims in published maps and institutional affiliations. 